\title{
EDITORIAL
}

\section{Onde Estamos? Para onde Vamos?}

A energia fóssil proporcionou nos últimos 200 anos um crescimento económico e um desenvolvimento tecnológico e populacional sem precedentes, resultando em grandes desafios ambientais e sociais. As florestas são a infraestrutura biológica mais importante a nível mundial e a principal fonte de recursos renováveis não-alimentares, substituindo os recursos fósseis não renováveis.

Os recursos florestais são, portanto, cruciais para construir uma bio economia circular que substitua a economia fóssil linear existente. Para além disso, a biodiversidade e os serviços relacionados com o clima, o solo e a água prestados pelas nossas florestas desempenham também um papel fundamental na resiliência do planeta. Na Europa existem cerca de mil milhões de hectares de floresta, que ascendem a 25 por cento do total mundial. Desde os anos 90 que a área florestal na Europa tem vindo a aumentar de forma constante, apesar de estar a decrescer de uma forma muito acentuada no resto do mundo.

O crescente impacto e complexidade das mudanças globais exigem contudo, um novo papel estratégico para as florestas na promoção da sua resiliência sócio ecológica. Numa Europa altamente urbanizada, onde as cidades são responsáveis por $80 \%$ da população e do consumo de energia, o papel das florestas (mais de $40 \%$ da área da UE) na economia e na valorização de recursos essenciais como a água, o solo e a biodiversidade, precisa de ser melhor compreendido, principalmente atendendo aos desafios atuais das alterações climáticas e do papel da gestão florestal na conservação da biodiversidade. Neste âmbito, são necessárias novas formas de governação que utilizem políticas holísticas e abordagens de gestão integrada para conciliar os objetivos da bio economia e da resiliência. 
A gestão florestal sustentável é por isso cada vez mais o mandamento de vários regulamentos nacionais, europeus e internacionais. A Conferência Ministerial para a Proteção das Florestas na Europa (MCPFE) tomou uma série de resoluções amplamente postas em prática, por exemplo, pela FAO e pela certificação florestal (PEFC 2004). Perturbações devidas às alterações climáticas, surtos de pragas (p. ex. escolitídeos) e danos causados por tempestades e incêndios florestais, são o tema de muitas propostas relacionadas com objetivos políticos. Por outro lado, o ponto de vista de que as florestas têm de ser preservadas, quer como reservatórios de carbono (os ecossistemas e produtos florestais sequestram atualmente cerca de $13 \%$ dos gases com efeito de estufa (GHG) na EU), quer pela sua biodiversidade (na UE pré-Brexit, cerca de $25 \%$ dos 28 nações faziam já parte da Rede Natura 2000) tornou-se um aspeto dominante. Neste contexto, é provável que a proposta de "Acordo Verde Europeu", da Comissão Europeia, lançada em Dezembro de 2019, afete a forma como as florestas irão ser tratadas nas próximas décadas. Contudo, existem grandes divergências no modo como a floresta deve ser encarada - recurso natural a ser gerido de forma sustentável vs ecossistema natural a ser protegido.

A região mediterrânica, em particular, fornece exemplos multifacetados do impacte negativo que as alterações climáticas, em conjugação com os incêndios florestais e as pressões socioculturais, podem originar na paisagem. A desflorestação, a degradação e a desertificação são processos de deformação do solo altamente associados às florestas no Mediterrâneo. Estas florestas, para além do papel fundamental que desempenham na regulação da água e da erosão do solo, caracterizam-se pela sua diversidade e carácter de utilização múltipla, com grande importância para o desenvolvimento rural, proporcionando benefícios económicos, não só da madeira (p. ex., construção, combustível), mas também de outros produtos, tais como cortiça, resina, frutos secos, forragem, cogumelos e caça, estabelecidos em sistemas mistos de utilização do solo (p. ex., produção de cortiça em combinação com a gestão do gado ou, árvores como proteção contra o vento em campos agrícolas).

A Europa irá assim enfrentar uma nova era de elaboração de políticas florestais após 2020. Será necessária uma estratégia e uma boa orientação política, para apoiar a implementação das metas que têm vindo a ser definidas. Alguns dos principais objetivos da política global de conservação da biodiversidade (p. ex., a Convenção sobre a Diversidade Biológica, Objetivos de Desenvolvimento Sustentável, os Estados Unidos Convenção-Quadro das Nações Unidas sobre Alterações Climáticas e o acordo de Paris) ainda não foram alcançados. 
$\mathrm{Na}$ arena da política global, desenvolvimentos comerciais relacionados, por exemplo, com a China, a Rússia e a América do Norte, terão também implicações importantes para o sector florestal europeu. Nomeadamente, terá de ser tomada uma decisão sobre se devem ser iniciadas negociações sobre um acordo juridicamente vinculativo acerca das florestas na Europa sobre a umbrela da Organização das Nações Unidas para a Economia A Comissão para a Europa (UNECE) terá de ser tomada em 2020.

Em Portugal, o papel que o sector florestal tem vindo a ter, no fornecimento de recursos naturais e na sustentação de inúmeras indústrias comerciais está bem documentado e reconhecido. Durante o século $X X$, a área de espaços florestais arborizados aumentou muito significativamente, no Continente, sobretudo devido ao sobreiro e pinheiro bravo até à década de 70 e ao eucalipto desde a década de 50. Processos equivalentes mas de dimensão diferente ocorreram também nos Açores e na Madeira. Por outro lado, a floresta em Portugal, para além dos produtos madeireiros baseados nas espécies dominantes, pinheiro e eucalipto, e da atividade corticeira, tem outros polos economicamente ativos a uma escala local (frutos secos, caça, pesca desportiva e turismo).

As últimas três décadas foram no entanto de grande turbulência para o sector. Fatores externos e internos contribuíram para criar uma imagem de altos riscos de investimento e de gestão a nível privado. A Estratégia Nacional para as Florestas (ENF), aprovada pela Resolução do Conselho de Ministros $\mathrm{n}^{\circ}$ 114/2006, de 17 de Agosto, recolocou as florestas na agenda política, uma década volvida sobre a publicação da Lei de Bases da Política Florestal (Lei n. ${ }^{\circ}$ 33/96, de 17 de Agosto) e na sequência do sobressalto coletivo provocado pelos incêndios florestais de 2003 e 2005.

Durante os últimos 100 anos, a investigação florestal na Europa acumulou uma riqueza de conhecimentos que correspondem aos ideais de uma gestão florestal sustentável. Contudo, desenvolvimentos recentes com uma implementação muito mais forte da satisfação dos três elementos de sustentabilidade (ecológica, económica e sociocultural), vieram a identificar importantes lacunas de conhecimento na nossa atual compreensão e necessidades de informação sobre as florestas e as paisagens florestais.

Governar as nossas florestas numa época de mudanças transformacionais torna o papel da investigação mais importante do que nunca. Isto requer uma nova investigação interdisciplinar ligando a ciência florestal a outras disciplinas 
de uso do solo e estudos urbanos, para criar uma base para políticas eficazes e integradas. Em particular, há a necessidade de apresentar informação sobre o nível de sustentabilidade utilizando uma melhor interface entre investigação e desenvolvimento, por um lado, e o resto da sociedade, por outro lado. A integração é aqui vista como um elemento-chave tanto dentro da comunidade científica (entre disciplinas), como na sociedade como um todo (entre as florestas e a sociedade).

Contudo, em Portugal, não há clareza suficiente sobre a forma como os objetivos da investigação florestal são fixados e atingidos. Os temas e programas de investigação devem funcionar a níveis descentralizados apropriados, planeados a longo prazo e com uma integração entre temas e programas.

A investigação e o desenvolvimento asseguram que aumentemos a produtividade e a sustentabilidade, que vejamos uma melhoria na qualidade de vida de todos os envolvidos no sector e que os nossos produtos continuem a ser competitivos a nível internacional. Acelerar o investimento em estratégias de investigação florestal garantirá a nossa capacidade humana e institucional para ver o sector no futuro e gerar avanços na tecnologia.

No entanto, a investigação e desenvolvimento em todo o sector florestal encontra-se atualmente num estado de pobreza e declínio. As atividades de I\&D sofrem de falta de visão e de coordenação nacional, de falta de financiamento público e de uma base de competências em técnicos e em investigadores especializados que está em clara redução.

Uma estratégia de investigação florestal deve ser criada, tanto a médio como a longo prazo (projetos de 3 anos são claramente insuficientes para o sector), que lide com conhecimentos básicos de estrutura, função e dinâmica das espécies, populações, ecossistemas e paisagens.

São necessários três tipos principais de recursos para a investigação florestal: humanos (cientistas, técnicos, outro pessoal), financeiros (os fundos para colocar a mão-de-obra em uso produtivo), e físicos (as infraestruturas, equipamento, edifícios, etc.) Contudo, a simples disponibilidade de recursos não garante o resultado de uma investigação boa e produtiva, nem mesmo a existência de capacidade para fazer essa investigação. Muito depende da forma como os recursos são organizados, geridos e utilizados ao longo do tempo.

O ponto de partida para implementar a ideia de medir, avaliar, integrar e comunicar os elementos de sustentabilidade das florestas aos decisores políticos, gestores e partes interessadas, é consolidar uma agenda de investigação transdisciplinar verdadeiramente integrada, que tenha em consideração basicamente os seguintes temas: 
- Construção de capital humano e instituições especializadas para um programa eficaz de inovação científica e tecnológica e para a gestão sustentável da floresta.

- Diminuição das limitações ao crescimento no sector e gerir os riscos de crescimento, nomeadamente os relacionados com as alterações climáticas, incêndios, pragas e doenças.

- Gestão da paisagem florestal para a sustentabilidade e desenvolvimento económico local, nomeadamente através do uso integrado do solo, gestão da água, novos modelos de povoamentos e comercialização dos produtos não-lenhosos.

- Melhoria do material genético para a instalação de novas florestas, nomeadamente na adaptação a condições de seca e pobreza de solos e aumento de produtividade.

- Desenvolvimento de novas empresas florestais, nomeadamente no mundo das fibras naturais, nos materiais de construção renováveis ou de novos produtos

- Promoção de um sector competitivo através da melhoria das condições de acolhimento da indústria e do manuseamento de materiais, em direção a uma sociedade circular, de desperdício zero

- Criação de novos cenários numa perspetiva económica, de mercado e tecnológica, designadamente na utilização eficiente dos recursos naturais, na diversificação das tecnologias e na implementação de energias renováveis (energia verde e biocombustíveis)

- Adoção de políticas e impactos regulamentares e desenvolvimento institucional a poiados no conhecimento adquirido, nomeadamente na valorização de serviços do ecossistema não lenhosos.

Edmundo Sousa

(Diretor da ex-Estação Florestal Nacional) 